\title{
Groundwater Use in a Global Perspective - Can It Be Managed?
}

\author{
Karen G. Villholth and Mark Giordano \\ International Water Management Institute, 127 Sunil Mawatha, Pelawatte, \\ Battaramulla, Sri Lanka
}

\section{Introduction}

Groundwater has long been second to surface water in terms of its importance for human use and the attention devoted to it by the general public and water sector managers. However, this picture is quickly changing as groundwater increasingly supplants surface water in many areas of the world as the primary and preferred source of water for all types of use, i.e. domestic, agricultural (crop and livestock) and industrial. This change is being driven by groundwater's inherently beneficial properties in terms of both quality and quantity combined with easy access through better and cheaper drilling and pumping techniques. While its 'in-stream' values, as is the case with rivers, have not been widely acknowledged, the critical role groundwater plays in maintaining important surface water systems, riparian and other types of vegetation as well as vital ecosystems is also increasingly recognized. However, this recognition has unfortunately emerged in many cases in a retrospective manner, as the signs of overdraft and degradation gradually become manifest in the depletion and deterioration of the associated aquifers, rivers, lakes, wetlands and other water-related ecosystems. Groundwater is surfacing, so to speak, in people's awareness mostly as a result of the increasingly observable problems rather than as a reaction of gratitude for all the benefits that it is providing humankind. The saying: 'You never miss your water till your well runs dry' is very suitable in this context. However, the question then turns to whether the impending accruing groundwater-related problems can be countered and curbed based on this increased general awareness and appreciation of the resource. Can groundwater use in today's world be actively managed, and how?

This chapter highlights some salient characteristics of groundwater as a fundamental resource for human existence, the contemporary use of the resource, particularly in agriculture, and the present challenges associated with its management in a local and global context. The objective is to summarize, in a kaleidoscopic and more philosophical way, the chapters presented in this volume, The Agricultural 
Groundwater Revolution: Opportunities and Threats to Development, and suggest answers to the above questions.

\section{The Contemporary Story of Groundwater Use}

Groundwater is generally a reliable and good quality water source, and with modern technology for drilling, electrification and pumping, it is widely accessible throughout most parts of the world today. In fact, these technological advances are primarily accountable for the recent, remarkable increase in global abstraction of groundwater. The history of global intensive groundwater use is less than 50 years old and much of the modern increase in global water use has been contributed by groundwater. Surface water use has remained constant or increased at a slower rate, simply because resources are running out or the feasibility of capturing and storing them is low. What is also remarkable about today's groundwater use is that the increase is continuing on a global scale, with only patches of declining or stagnating trends. Global aquifers hold an enormous water reserve that is several times greater than surface water resources (UN/WWAP, 2003). Groundwater could, in principle, be exploited at an aggregate level that is higher than it is today. However, the overriding limitations to further groundwater use in the future will continue to be environmental problems associated with the desiccation of aquifers and the socio-economic problems related to increasingly unequal access, especially in developing countries, to the resource as the groundwater levels decline and the aquifers become contaminated as a side effect of intensive use and generally increased pressure on natural resources.

In addition, the classical problem of uneven geographical distribution of surface water resources also applies to groundwater, at least at more regional scales, and the general mismatch between the location of high demand (highpopulation, potential-intensive agricultural areas) and groundwater availability is very real and relevant. Often, and logically, groundwater is developed and in further demand in dry and semiarid areas where surface water is scarce or seasonal. But such regions are typically underlain by non-replenishable or slowly replenishable aquifers unfit for intensive exploitation, putting a natural break on unlimited growth in use. Likewise, half of the world's population today lives in coastal areas (Post and Lundin, 1996) where groundwater traditionally provided secure and adequate water supply. However, these areas are increasingly threatened by deterioration of water quality due to salt water ingress from widespread and intensive groundwater extraction (Kaushal et al., 2005).

It is essential to focus on the agriculture in the context of global groundwater use for the simple reason that volumes used in this sector significantly exceed other uses, e.g. industrial and domestic, at the global scale. Especially in many arid and semiarid regions of the world that coincide with nations in development, such as India, North China and Pakistan, groundwater use is critical for food security. Here the management challenges are manifold in the sense that a balance between securing groundwater-dependent livelihood and ensuring the long-term environmental sustainability is required. But even in more developed countries in less arid regions such as the USA, Australia and Mexico, as well as 
in Mediterranean countries like Spain, groundwater supplies significant water for agricultural use and its management presents great challenges. High dependence on groundwater also occurs in humid countries, but more for industrial and domestic uses (e.g. Japan, the former USSR and north European countries like Denmark and the Netherlands (Margat, 1994)). Here, the volumes drawn are generally not threatening the resource base from a quantity point of view - it is more water quality issues that present the major challenges.

Yet another category of countries includes those that potentially could benefit from an intensification of groundwater use for agriculture and associated development, such as parts of sub-Saharan Africa (see Masiyandima and Giordano, Chapter 5, this volume), Nepal and eastern India (see Shah, Chapter 2 , this volume). In these cases, present limitations to such development seem to be associated with poor energy access, lack of infrastructure and market access, lack of credit possibilities and possible cultural or demographic barriers.

Groundwater is now surpassing surface water in importance in many regions of the world, in terms of water supply for irrigation. The 2005 FAO AQUASTAT database on irrigated area lists the countries Algeria, Bangladesh, India, Iran, Libya, Saudi Arabia, Syria and Yemen, as those depending more on groundwater than surface water for their irrigation. Expanded groundwater use in a global context can be seen as a second step in the continued and accelerated quest for water for human development. Basically, surface water was accessed, appropriated and allocated first, as this resource was more visible and readily available and most human settlements confluenced with rivers and streams where water was traditionally secured. As surface water resources are being exhausted and strained in terms of quality and the options to dam them have diminished, groundwater has become the second-generation resource to be captured and appropriated.

Taking this analysis further and linking it with the general hydrological cycle, there is now a trend towards focusing on rainwater as the 'new' water source to capture for direct use as well as for storing and optimizing. What is interesting in this scheme is that in a sense we are moving progressively backwards, or upstream, in the hydrological cycle to look for water, because rainwater feeds groundwater and groundwater feeds surface water (Fig. 17.1). More importantly, there is a tendency, amongst lay people but also water professionals, to look at water sources independently and consider them as isolated, new resources that can be explored without affecting the others. One example is the artificial recharge movement in India that attempts to capture rainfall and runoff for local replenishment of aquifers for the improvement of livelihood and to counteract groundwater declines (see Sakthivadivel, Chapter 10, this volume). However, referring to Fig. 17.1, it is obvious that these sources are intricately interlinked, and capturing one will diminish the availability of the downstream sources. Realizing this and respecting this simple, but fundamental, upstream-downstream and mass balance concept is crucial to any kind of water resources management. Following these arguments, it is also clear that groundwater cannot be managed in isolation and that integration of all water resources needs to be considered in overall assessment and planning.

Hence, the issue of groundwater use today is essentially not technical but managerial - how to balance the benefits of use with the associated negative 


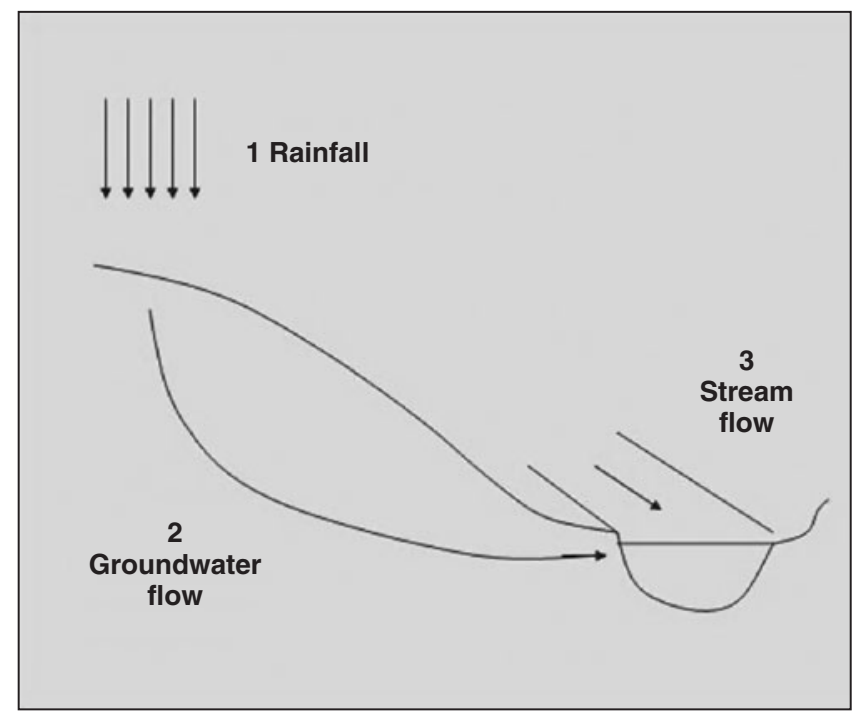

Fig. 17.1. Groundwater as a sequential component of the hydrological cycle.

impacts? Although this is increasingly being realized by water managers, practitioners and scientists, it is proving to be one of the most challenging tasks for humankind as we move into the 21 st century as population increases, demand for higher living standards in the developing world and climate change with associated increases in extreme events all mix together to put higher pressures and threats on already strained resources, including groundwater.

While paradigms for groundwater management are slowly emerging and various models are investigated and tested (see Schlager, Chapter 7; Kemper, Chapter 8; and Moench, Chapter 9, this volume), it is also clear that from actual cases that management based on strict control of groundwater development and use (demand management) is generally difficult to implement and enforce, perhaps especially in developing countries (see Shah, Chapter 2; and Wang et al., Chapter 3, this volume). This is to a large extent attributable to the fact that groundwater has many 'open-access' properties, leaving little incentive for users to curtail their use because they cannot fully capture the associated benefits (see Schlager, Chapter 7, this volume). The generally easy access to the resource for individuals combined with this fact actually presents the core dilemma in groundwater management, and as of today there seems to be very few examples of solutions addressing this dilemma.

\section{Drivers of Groundwater Development}

Two fundamental human drivers for groundwater development for irrigation may be summarized as survival and profit. These two drivers may in fact be considered as extremes of a continuum governed primarily by the stage of development 
of a certain region, exemplified by the small-scale farmer in central India trying to improve the outcome of his or her small rain-fed plot by supplemental irrigation from groundwater on one end, and a large-scale commercial mid-west farmer in the USA optimizing his maize yield and speculating on world food prices on the other end. The large-scale users, of course, exert the largest abstraction pressure on the resource per person. However, when many small-scale users are conglomerated within larger areas, like in parts of India and China, the aggregate effect may be similar (Fig. 17.2). Furthermore, when large numbers of users are involved, as is often the case in countries with limited resources for monitoring and governance, cooperative management becomes difficult. The ironic fact is that both of these extreme cases represent situations in which groundwater is considered 'overabstracted' today, and the national and local authorities are concerned about the sustainability of the present-day exploitation of the resource.

This spectrum view of groundwater use is a simplification of the reality but serves to show that intensive groundwater exploitation in agriculture today is a common global phenomenon across quite different socio-economic settings, resulting in essentially the same types of physical or environmental impacts. Although the scope and capability for addressing the problems is potentially more favourable for countries like Spain, the USA and Australia (see, respectively, Llamas and Garrido, Chapter 13; Peck, Chapter 14; and Turral and Fullagar, Chapter 15, this volume), it is clear that by no means is the curbing of groundwater intensive use easy in any setting.

Figure 17.2 gives a sketch of the spectrum of groundwater use as a function of development. 'Use' and 'development' here are broad illustrative terms, not put to any quantitative scale.

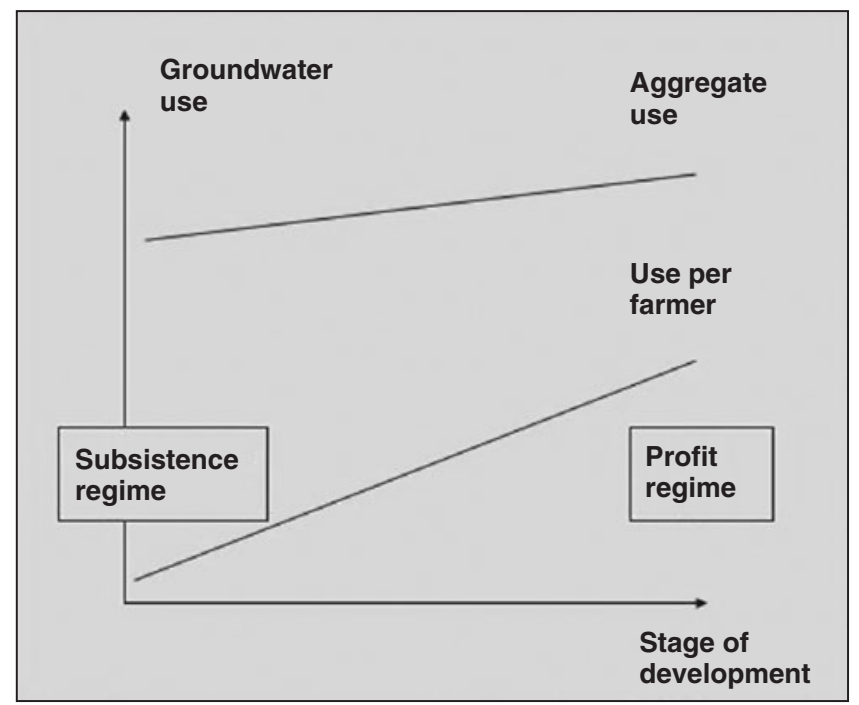

Fig. 17.2. Sketch of spectrum of groundwater use as a function of development. 


\section{Groundwater Overexploitation - What Is That?}

With groundwater resources increasingly being utilized to fulfil human requirements and the demands seemingly insatiable, the question of sustainability naturally arises. Within the last decade or so, the debate around defining limits to sustainable groundwater use has intensified (Custodio, 2002; see also Llamas and Garrido, Chapter 13; and Turral and Fullagar, Chapter 15, this volume). Basically, there is no clear and unambiguous definition of such a limit, be it designated 'sustainable yield' or 'exploitable groundwater'. However, there is a growing consensus that such a concept is a valuable tool for legitimization, informed discussion and consensus building on management: defining areas where additional groundwater use should be curtailed or where investment in management, rather than development, should be made. There is also a growing recognition that such a concept is not restricted to an assessment of the physical availability of groundwater in a certain area of concern. Equally important is the assessment and reconciliation of the positive and negative impacts of increased utilization on society as well as the environment. Examples where such approaches are taken up more systematically as part of the national groundwater management approaches include countries such as Australia, India and South Africa. The effectiveness of such an approach hinges on its credibility to the stakeholders and decision makers. Furthermore, realizing the dynamics of society and the gradual improvements in information and data availability, the assessments should be ongoing (see Turral and Fullagar, Chapter 15, this volume).

\section{Recognition of Groundwater Problems}

There is a large gap in the level of information and documentation of the national and subnational state of groundwater between developed and developing countries (see van der Gun, Chapter 16, this volume). Furthermore, literature from developing or transition countries is more often in local languages as in China and Latin America (see Wang et al., Chapter 3; and Ballestero et al.,Chapter 6, this volume) or in the grey literature as in sub-Saharan Africa and Central America (see Masiyandima and Giordano, Chapter 5; and Ballestero et al., Chapter 6, this volume), impeding general access to it. Nevertheless, literature on groundwater problems around the world is increasingly reflecting the general upward trend in use and its impacts. Rather than repeating these here, a reference to summary papers is given which covers both developed and developing countries (Burke and Moench, 2000; Danielopol et al., 2003; FAO, 2003; Llamas and Custodio, 2003; Moench et al., 2003; Morris et al., 2003; Moench and Dixit, 2004; Shah et al., 2006; see also the five regional chapters in this volume).

Most of the scientific community agrees that there is a problem with presentday groundwater use in many regions around the world, basically because of the way the groundwater resource itself, the environment and poor segments of the societies, especially in developing countries, are adversely affected. The 
latter refers to the inability of poor or disadvantaged people, in general, to cope with degradation of natural resources, both because they are often more directly dependent on them for their livelihood and because they are less capable of adapting to the increased competition for the resources and are most often left with poor access to poor-quality water, even for their basic needs.

It is interesting to consider the fact that intensive groundwater use over just one generation, or essentially the last 3-4 decades, has drawn down underground water resources to an unprecedented level in human history, and there is no likelihood that water management in the future will make it possible to revert to earlier levels, or even maintain status quo. Basically, this blue underground treasure, which is only partially replenishable, is permanently lost and with it, valuable wet ecosystems as well as an important buffer capacity against droughts. Again this impact strikes harder in already marginal and resource-stressed areas and regions of the world where poor people already tend to accumulate.

Groundwater pumping most often occurs in an uncontrolled and indiscriminate manner, be it in developed or developing countries. Entitlement to groundwater is most often associated with access to land and financial resources (for drilling and pumping costs) more than formal rights and regulations to the resource itself. This can result in the classic 'tragedy of the commons' problem often associated with groundwater, but also misuse from other perspectives. For example, high-quality groundwater might be used for agriculture while poor people seek drinking water supplies from contaminated surface sources.

Despite the recognition of the problems associated with intensive groundwater use in many countries among the scientific community, there may not be the same consonance regarding the groundwater problems among decision makers and actual groundwater users, and even then it may be very difficult to reach agreement on primary problems, root causes and key issues responsible for the problems, ${ }^{1}$ let alone the remediation measures to put in place. This clearly illustrates that the management of groundwater needs to consider the whole spectrum of users as well as direct and indirect stakeholders, including the 'silent' or subordinate users, namely the environment and the disadvantaged groups of society (often represented only through international environmental organizations, e.g. IUCN, WWF and Ramsar, or local or national non-governmental organizations (NGOs)). It also illustrates that knowledge of the processes and the cause-effect relationships are required at all levels, as well as participation, communication and negotiation.

\section{Challenges to Groundwater Management}

The fact that groundwater use continues to grow on a global scale, only occasionally levelling off as a reactive rather than proactive response to perceived severe impacts in some areas, portends poorly for the overriding question, as raised in the introduction, of whether groundwater can be managed.

In developing countries, farmers make up the majority of the population. When their livelihoods, and sometimes their very lives, depend on groundwater, they understandably resist uncompensated measures to curtail use. In 
developed countries, though the number of groundwater-using farmers is lower, the continued operation of their farms, and the value of their often substantial investments, can sometimes only be maintained if the groundwater continues to flow. From another perspective, groundwater can fall within broader political agendas, making efforts to manage use secondary to other concerns, such as supporting a certain population or political group irrespective of obvious natural resource encroachments (see Allan, Chapter 4, this volume). To various degrees in each of these cases, the social and political will as well as the economic backing for effective groundwater management may not be in place.

As an alternative to direct management, water-saving irrigation techniques have been promoted to improve food production per unit of water input, but it is questionable whether such approaches significantly reduce stress on groundwater resources. This is because such methods are often associated with the shift to more intensive cultivation, using more water-intensive crops, higher levels of chemical input and better soil-conservation techniques. So crop yields increase per area under cultivation and per water input. But overall, groundwater use may have actually increased because of the intensification. The fundamental problem of how to feed an ever-increasing global population while at the same time maintaining or even decreasing the water requirements is one that puzzles planners as well as scientists (Comprehensive Assessment of Water Management in Agriculture Synthesis Report, forthcoming 2006).

In a sense, much wealth creation and poverty reduction has been derived on a loan that will never be directly paid back. There is a danger that the poverty-reducing potential of groundwater will be lost, making societies more vulnerable to climate changes and extreme events. There is a major challenge in securing basic water needs to people in developing countries who depended to a large extent on sustainably replenished shallow wells that are now out of reach. The primordial role of drinking water needs to ensured, for example, by having deep, protected wells for drinking and shallow wells for irrigation (and not the other way around as is often the case today in rural areas), or by zoning of areas with precedence for drinking water.

The link between groundwater use in agriculture and for urban areas is also becoming increasingly apparent and needs much more research and management focus. Realizing that irrigation generally poses less strict requirements on water quality compared to urban use (for domestic and industrial uses) obviously suggests prioritizing urban water use and making irrigated agriculture the second in line in a cycle of water reuse. The challenge in many cases becomes one of sending treated wastewater back upstream in the catchment as irrigation areas are often upstream while cities are located downstream along rivers or in coastal areas. Obviously, this is a complex and costly intervention, but one that can be further explored when economic and socio-economic conditions are right (see Turral and Fullagar, Chapter 15, this volume, for an example from Australia).

\section{Conclusions}

Many of the problems of groundwater management may seem insurmountable. However, paradigms for their solution are being articulated. These 
range from community management approaches (see Schlager, Chapter 7; and Sakthivadivel, Chapter10, this volume) hinging on local initiatives, social norms and informal agreements, to more formalized laws and associated formal rights and regulations within and outside the groundwater sector (see Kemper, Chapter 8; and Shah, Chapter 11, this volume), to a focus not on resource management itself but rather to people's adaptive ability to overcome stress caused by groundwater decline and degradation (see Moench, Chapter 9; and Mudrakartha, Chapter 12, this volume) and turn today's groundwater use into an opportunity for tomorrow's improved livelihood.

In considering our options for sustainably managing groundwater in the future, two key points should be remembered. First, it is as important to consider the socio-economic and sociopolitical characteristics of any groundwaterusing society as the physical characteristics of groundwater resources in any proposed management solutions. A solution for places with large numbers of small farmers may be inappropriate for other locations with small numbers of large farmers and vice versa. Similarly, that which might work in a country with a strong central government and significant financial resources for enforcing regulations may work less well in a country where political power is more diffuse or financial resources are scarce. Second, the 'groundwater revolution' has had a short history. The development of institutions for resource management in general and for a complicated, often 'invisible', resource like groundwater can be expected to take time and experimentation. The initial growth in agricultural groundwater use has brought benefits to millions, perhaps billions, of farmers and consumers around the world. The goal now is to ensure that those benefits continue into the future as we shift the focus from groundwater development to long-term groundwater management. Although some opportunities have perhaps already been lost, there is still time to learn from experiences around the world on how to proceed, provided increased focus, awareness and political will is exercised.

\section{Note}

1 Local groundwater-irrigating farmers may ascribe the decrease in water availability to general drought phenomena. Managers may blame the farmers for the excessive pumping and feeling no responsibility towards the issue.

\section{References}

Burke, J.J. and Moench, M.H. (2000) Groundwater and Society: Resources, Tensions and Opportunities. United Nations Publications, Sales No. E.99.II.A.1, ISBN 92-1-104485-5.

Comprehensive Assessment of Water Management Synthesis Report (forthcoming 2006).
Custodio, E. (2002) Aquifer overexploitation: What does it mean? Hydrogeology Journal 10, 254-277.

Danielopol, D.L., Griebler, C., Gunatilaka, A. and Notenboom, J. (2003) Present state and future prospects for groundwater ecosystems. Environmental Conservation 30(2), 104-130. 
FAO (2003) Groundwater Management - The Search for Practical Approaches. Water Reports 25. FAO (Food and Agricultural Organization), ISBN 92-5-104908-4.

Kaushal, S.S., Groffman, P.M., Likens, G.E., Belt, K.T., Stack, W.P., Kelly, V.R., Band, L.E. and Fisher, G.T. (2005) Increased salinization of fresh water in the northeastern United States. National Academy of Sciences of the USA 102(38), 13517-13520.

Llamas, R. and Custodio, E. (eds) (2003) Intensive Use of Groundwater: Challenges and Opportunities. A.A. Balkema, Rotterdam, The Netherlands, p. xii.

Margat, J. (1994). Groundwater operations and management. In: Gibert, J., Danielopol, D.L. and Stanford, J.A. (eds). Groundwater Ecology. Elsevier, Amsterdam, pp. 505-522.

Moench, M. and Dixit, A. (2004) Adaptive Capacity and Livelihood Resilience: Adaptive Strategies for Responding to Floods and Droughts in South Asia. ISET (Institute for Social and Environmental Transition), Nepal, India/Boulder, Colorado.

Moench, M., Burke, J. and Moench, Y. (2003) Rethinking the Approaches to Groundwater and Food Security. Water Reports 24. FAO (Food and Agricultural Organization), ISBN 92-5-104904-1.
Morris, B.L., Lawrence, A.R.L., Chilton, P.J.C., Adams, B., Calow, R.C. and Klinck, B.A. (2003) Groundwater and Its Susceptibility to Degradation: A Global Assessment of the Problem and Options for Management. Early Warning and Assessment Report Series, RS. 03-3. UNEP (United Nations Environment Programme), Nairobi, Kenya. ISBN 920807-2297-2.

Post, J.C. and Lundin, C.G. (1996) Guidelines for Integrated Coastal Zone Management. World Bank report, ISBN 0-8213-3735-1.

Shah, T., Villholth, K.G. and Burke, J.J. (2006) Groundwater Use in Agriculture: A Global Assessment of Scale and Significance for Food, Livelihoods and Nature. Comprehensive Assessment, IWMI, International Water Management Institute.

Stenbergen, F. van (2003) Local Groundwater Regulation. Water Praxis Document Nr. 14. Arcadis, Euroconsult.

UN/WWAP (United Nations/World Water Assessment Programme) (2003) UN World Water Development Report: Water for People, Water for Life. UNESCO (United Nations Educational, Scientific and Cultural Organization) and Berghahn Books, Paris. 